\title{
Potencial dos resorts brasileiros como reveladores e difusores das diversidades de expressões culturais locais-regionais
}

\section{Potential of Brazilian resorts as revealers and diffusers of local and regional cultural expressions diversities}

\author{
Jorge Luiz Amaral de Moraes (MORAES, J. L. A. de)* \\ Suzana Ney Helbig (HELBIG, S.N.) ${ }^{* *}$
}

\begin{abstract}
RESUMO - O objetivo principal deste estudo foi analisar as potencialidades dos resorts brasileiros como difusores das diversidades de expressões socioculturais locais-regionais aos turistas. A pesquisa foi realizada por meio de entrevistas com os gerentes desses empreendimentos para identificar eventuais relações com o patrimônio sociocultural e ambiental da região e por meio da estadia dos pesquisadores nesses estabelecimentos. Os resorts pesquisados têm como uma de suas principais características a ambientação junto à natureza como parte integrante da experiência da hospedagem, onde o paisagismo acompanha as atividades de entretenimento, gastronômicas, de descanso e de contemplação ligadas aos aspectos regionais-locais. Verificou-se que há a possibilidade de um aprofundamento da relação positiva das características dos resorts brasileiros com a preservação do patrimônio ambiental e sociocultural local-regional, muito atrativa para turistas estrangeiros e brasileiros, gerando benefícios para as populações locais.
\end{abstract}

Palavras-chave: Expressões culturais locais; Turismo regional; Resorts; Cultura local; Difusão cultural.

\begin{abstract}
The main objective of this study was to analyze the potential of Brazilian resorts as diffusers of local and regional sociocultural expressions diversities to tourists. The research was carried out by interviews with the managers of these resorts in order to identify possible relations with the socio-cultural and environmental regional heritage and also by the researchers hosting in these establishments. The resorts surveyed have as one of their main characteristics the setting in the nature as an integral part of the lodging experience, where landscaping goes along with the activities of entertainment, gastronomy, resting and contemplation linked to the regional and local aspects. It was verified that there is a possibility of a deepening of the positive relation of the characteristics of the Brazilian resorts with the preservation of the local and regional environmental and sociocultural heritage, very attractive for foreign and Brazilian tourists, generating benefits for the local populations.
\end{abstract}

Key words: Local cultural expressions; Regional tourism; Resorts; Local culture; Cultural diffusion.

\footnotetext{
* Graduado em Agronomia pela Universidade de Passo Fundo (UPF). Mestrado em Economia Rural pela Universidade Federal do Rio Grande do Sul (UFRGS). Doutorado em Desenvolvimento Rural pela UFRGS. Professor do Curso de Turismo e do Programa de Pós-Graduação em Desenvolvimento Regional da FACCAT (Faculdades Integradas de Taquara). Endereço: Rua Tomaz Flores, 296, apto 301, Independência. Porto Alegre, Rio Grande do Sul, RS. CEP: 90.035-200. E-mail: jmoraes12@gmail.com

** Graduada em Administração pela FACCAT (Faculdades Integradas de Taquara). Mestrado em Desenvolvimento Regional pela FACCAT. Professora do Instituto Federal de Educação, Ciência e Tecnologia do Rio Grande do Sul (IFRS). Endereço: Rua Pinheiro Machado, 1800, Jardim do Prado, Taquara, Rio Grande do Sul, RS, Brasil. CEP: 95.600-000. E-mail: suzananh@hotmail.com 


\section{INTRODUÇÃO}

O segmento do turismo, com seus benefícios diretos e indiretos, apresenta-se como alternativa para o desenvolvimento regional, ocupando posição de destaque no cenário global, uma vez que impacta significativamente na geração de emprego, renda, divisas e, ainda, por ser um agente potencial para a valorização e promoção da diversidade de expressões culturais. A demanda mundial pelo turismo ultrapassou 1 bilhão de viajantes em 2012, quando teve um crescimento anual de 4,0\% em relação ao ano anterior. Em 2013, o setor turístico era responsável por cerca de $9 \%$ do total de empregos gerados no Brasil e, segundo o Plano Nacional de Turismo, a projeção para 2023 é de 10,6 milhões de empregos diretos e indiretos, aproximadamente $9,5 \%$ do total de empregos gerados no país (BRASIL, 2013).

Acompanhando o crescimento dos índices turísticos no mundo, os meios de hospedagem também vêm crescendo e gerando novos investimentos no Brasil. Estima-se a existência de mais de 300 resorts no Brasil, de acordo com o que é oferecido através de agências de turismo como, por exemplo, o Hotel in Site, um site de agenciamento de hotéis que contempla 17.000 alternativas para 5.700 cidades, distritos e destinos turísticos no Brasil (GUIA DE HOTÉIS BRASIL, 2015).

Parte desses resorts voltam suas ações para o entretenimento de crianças e jovens dentro da perspectiva de educação ambiental, econômica e sociocultural o que sinaliza um novo mercado, que busca a conscientização por meio de atividades de lazer e cultura, cumprindo com os quesitos das Normas Brasileiras n 15.401. Segundo pesquisa do IBGE (2013), no Brasil 7,8\% das empresas estão ligadas à cultura, o que corresponde a 400 mil empresas e outras organizações, empregando 2,1 milhões de pessoas, das quais 73,5\% são assalariadas e recebem em média $30 \%$ a mais do que empregados de outros setores.

A intensificação da procura por esse meio de hospedagem é contínua, principalmente pelo fato de que estes empreendimentos dispõem de uma estrutura completa de lazer, esportes variados e instalações para eventos e conferências; além de, normalmente, estarem localizados em áreas de incontestáveis belezas naturais e disporem de uma segurança bem superior aos demais empreendimentos (OMT, 2001). Na visão de Mill (2003, p. 11), os resorts são uma combinação de três elementos básicos: "atrações recreativas para atrair os hóspedes; hospedagem e serviços de alimentação e bebidas a serem oferecidos para pessoas que estão longe de suas casas; atividades para ocupar os hóspedes durante sua estadia". Barbosa (2005, p. 12) afirma que "os resorts são bastante criticados devido à capacidade de controlar e manter o turista dentro do espaço e não contribuir com o seu entorno, uma vez que muitas vezes o 
contato com a comunidade local é inexistente".

No entanto, entende-se que a cultura local pode ser utilizada estrategicamente, contribuindo para o crescimento da economia regional e para o desenvolvimento regional. Porém, para tanto, o setor precisa de ações diferenciadas, principalmente no que tange ao apoio à produção e difusão de atividades e expressões culturais. Neste quesito, o turismo e a cultura estão ainda em uma fase muito embrionária, uma vez que somente após a Carta de Intenções celebrada entre a UNESCO, o Brasil e outros países é que se começou a pensar a cultura como estratégica para ações voltadas para a alavancagem econômica.

Desde então, a cultura passou a ser vista também como promotora da inclusão social e com potencial para gerar postos de trabalho e renda. No intuito de desenvolver o turismo e proteger e promover as expressões culturais locais e regionais, vários segmentos envolvidos do poder público e setor privado, organizações da sociedade civil, terceiro setor, instituições de ensino e turísticas e autores consagrados vêm dando suas sugestões quanto às ações necessárias para atender este objetivo.

Este estudo analisa a relação entre a questão da diversidade de expressões socioculturais e o turismo, tomando como amostragem alguns resorts brasileiros, um de cada uma das macrorregiões do país. Conforme afirma Yúdice (2006), a cultura passou a ser uma espécie de recurso, de instrumento, ou seja, passou a ser utilizada como ferramenta para ativar "o potencial de desenvolvimento local de certas localidades, além de servir de vetor de o exercício da cidadania”. Assim, é primordial que setores de desenvolvimento do país voltados para o turismo, a educação e a cultura, estejam organizados e que seus planos de governo abordem conjuntamente ações preventivas, executivas e protetoras no contexto da difusão da diversidade de expressões culturais para que os indivíduos e povos possam ter asseguradas as suas crenças e valores.

O objetivo principal deste estudo foi analisar as potencialidades dos resorts brasileiros como cenários reveladores e difusores das diversidades ambientais e de expressões socioculturais locais e/ou regionais aos turistas que ali se hospedam e usufruem dos serviços e bens (materiais e imateriais) postos a sua disposição. Mais especificamente, buscou-se contextualizar as ações entre os setores turístico e cultural, com ênfase nas expressões socioculturais e ambientais legalmente registradas e comuns entre a região onde os resorts estão situados, assim como, examinar se existe nesses meios de hospedagem a preocupação com a difusão das expressões socioculturais locais ou regionais.

Além desta introdução, apresenta-se, na seção dois, a contribuição do mercado turístico e da diversidade cultural para o desenvolvimento regional-local e uma contextualização das 
políticas públicas próprias de cada um desses setores e os pontos em comum entre as mesmas. Em seguida descreve-se a metodologia utilizada para o estudo. Na seção 4, são apresentados os resultados da investigação em relação à diversidade cultural-regional nos resorts brasileiros e apresentam-se as características individuais de cada um dos resorts que representam as macrorregiões brasileiras. Por fim, são apresentadas as considerações finais sobre os resultados do estudo.

\section{TURISMO, CULTURA E DESENVOLVIMENTO REGIONAL}

O turismo é considerado uma alternativa eficiente para o desenvolvimento regional, tanto em nível mundial, como nacional ou local, uma vez que impacta significativamente a geração de emprego e renda. De acordo com Barbosa (2008), a Organização das Nações Unidas caracteriza o turismo sustentável como aquele que satisfaz as necessidades dos turistas, da indústria turística, do ambiente e das comunidades receptoras, levando em consideração todos os seus impactos atuais e futuros, em termos econômicos, sociais e ambientais. O mesmo autor afirma, ainda, que a sustentabilidade deve ser pretendida por todos os tipos de turismo, em todos os destinos, e que esta talvez seja alcançada se houver uma gestão eficiente e eficaz, capaz de gerar equilíbrio entre os aspetos econômicos, sociais, culturais e ambientais.

Os princípios que constituem a referência nacional para o turismo sustentável, estabelecidos pelo Conselho Brasileiro para o Turismo Sustentável (CBTS) que estão descritos na norma brasileira ABNT NBR 15.401 constituem-se em respeitar a legislação vigente, garantir os direitos das populações locais, conservar o ambiente natural e sua biodiversidade, considerar o patrimônio cultural e valores locais, estimular o desenvolvimento social e econômico dos destinos turísticos, garantir a qualidade dos produtos, processos e atitudes e, por fim, estabelecer o planejamento e a gestão responsáveis (ABNT, 2012).

Para Pereira (2017), mais recentemente foi necessário criar a categoria de patrimônio imaterial e intangível, fazendo com que a definição de patrimônio tivesse que ser ampliada, "para além da sua definição convencional de monumentos, prédios, espaços urbanos, objetos" (PEREIRA, 2017, p. 5). Para a autora acima, o patrimônio natural ou ambiental é parte do patrimônio cultural, por isso esse entendimento foi incorporado neste estudo, principalmente quando se busca informações empíricas em estabelecimentos turísticos, cercados por matas e populações indígenas no seu entorno, como os resorts representativos das macrorregiões 
Centro-Oeste e Norte. Portanto, estão inseridos em locais ou regiões formadas por ambientes naturais e dentro de uma perspectiva sociocultural.

Com o crescimento dos meios de hospedagem, cresceram também as preocupações das organizações no setor do turismo, não só com a satisfação das necessidades e desejos de clientes, cada vez mais exigentes, mas também, com o impacto que suas atividades, produtos e serviços podem ter no desenvolvimento sustentável do turismo. Assim, esses empreendimentos devem estabelecer e manter um sistema de gestão da sustentabilidade que assegure e mantenha o atendimento ao Turismo Sustentável (CBTS), por meio da NBR 15.401.

De acordo com o documento elaborado no âmbito do convênio ABNT/SEBRAE (2012) para que o turismo seja considerado sustentável ele deverá atender às dimensões ambientais, econômicas e socioculturais, considerados na Norma NBR 15.401 e no Guia que orienta os meios de hospedagem na implantação do Sistema de Gestão da Sustentabilidade.

A dimensão sociocultural, com a qual o objeto deste estudo está mais fortemente relacionado, inclui as comunidades locais, a geração de trabalho e renda, as condições de trabalho, os aspectos culturais, a saúde, a educação e populações tradicionais, como as indígenas, por exemplo, na macrorregião Norte. Estas questões servirão de base para a avaliação das respostas das entrevistas com os gerentes dos resorts que compõem a amostra da pesquisa.

Para Carlos (2007) o desenvolvimento está relacionado à afinidade entre o local (por exemplo, a região em que um resort está situado), e o global, desejada pelos turistas. Eles valorizam a singularidade do local, mas querem adicionar a ela peculiaridades de outros lugares, o que não quer dizer que devam ser iguais a outros lugares. Os produtos turísticos podem encantar justamente por meio dos seus diferenciais, porém devem seguir certas atividades e serviços que são padrões mundiais onde surgem, por exemplo, os chalés suíços, a cozinha internacional e as massagens de diversas origens. A exposição desorientada pode comprometer a sua identidade, desvalorizar as expressões culturais, depredar o meio ambiente, comprometendo desta forma, o futuro das próximas gerações.

Portanto, tão importante como entender a diversidade de expressões socioculturais, é saber como esta é percebida, ou seja, entender um pouco sobre a percepção e de que forma ela se manifesta por meio dos sentidos. No momento em que o resort oferece um produto ou serviço (objetos culturais), deve-se entender e compreender a maneira como eles (objetos) são percebidos pelos seus hóspedes, os turistas e sujeitos. Se toda viagem encerra um aspecto cultural, na medida em que o turista entra necessariamente em contato com um ambiente distinto daquele que caracteriza seu "habitat", passa a ter sua intenção voltada para conhecer culturas distintas da sua, o que caracteriza o turismo por ser cultural. 
O tema da "diversidade cultural" surgiu da discussão acerca da promoção e proteção das identidades culturais locais e regionais, uma vez que, com a globalização, é visível a intensificação do intercâmbio cultural material, como a comercialização de mercadorias, e imaterial, como o conhecimento ou saber-fazer local. Assim, órgãos nacionais e internacionais, como o governo federal e a UNESCO, alinharam as políticas públicas e passaram a articular estas ações, na busca de resultados positivos para o setor turístico e cultural. A diversidade cultural passou a ter mais visibilidade após a Declaração Universal da Unesco, de 2002, e de uma convenção internacional da Unesco, de 2005. No Brasil, já existem leis e normas tratando sobre a matéria, como o Decreto $n^{\circ}$. 3.551, de 4 de agosto de 2000, que instituiu o Registro de Bens Culturais de Natureza Imaterial e criou o Programa Nacional do Patrimônio Imaterial (PNPI), que consolidou o Inventário Nacional de Referências Culturais (INCR).

A partir desse novo contexto legal foi possível uma adequação do turismo às necessidades de um novo consumidor, ou seja, o turista que considera o ambiente e a cultura local de destino como experiência em sua viagem. Mesmo que o seu objetivo principal não seja o turismo cultural, nem a experimentação da cultura viva, é possível que o turista possa perceber a cultura local por meio de revelações da história regional, dos saberes e fazeres, assim como, de demonstrações de suas mais diversas expressões socioculturais. Estas expressões podem ser percebidas pela gastronomia, música, danças e obras de arte no destino turístico visitado, que no caso desta pesquisa, são os resorts, podendo incluir ou não o seu entorno.

\section{METODOLOGIA}

Para que fosse possível responder se os resorts podem ou não serem considerados difusores da diversidade de expressões socioculturais abordou-se o tema em duas etapas de coleta de dados e informações. Na primeira etapa foi realizada uma busca de dados e informações sobre esse meio de hospedagem, inicialmente fez-se um levantamento desse tipo de empreendimento no Brasil por meio do site que possui a maior oferta no mercado, o hotel in site. Ao mesmo tempo, buscou-se no CADASTUR as informações necessárias para relacionar os resorts por região e, de acordo com critérios pré-estabelecidos e descritos abaixo, escolher um resort de cada macrorregião do país para servir de amostragem para a segunda etapa da coleta de informações do estudo, a pesquisa de campo. Esta foi realizada no primeiro semestre de 2016, quando um dos pesquisadores viajou e ficou hospedado por 3 a 5 dias, com todos os custos financiados com recursos próprios, em cada um dos resorts selecionados como sendo 
representativo das macrorregiões brasileiras. Essa pesquisa de campo dividiu-se em dois momentos: na chegada em cada um dos resorts visitados foi realizada uma entrevista utilizando um roteiro com questões abertas para os gerentes desses empreendimentos, de forma que estes fizessem uma descrição ou relato das principais características do empreendimento que identificassem alguma relação com a cultura local ou com patrimônio sociocultural local ou da região. Em seguida, foram realizadas visitas ao entorno do resort, indicadas como indispensáveis para o conhecimento local pelos turistas.

A pesquisa empírica concentrou-se em detectar e observar as possíveis interações entre o objeto de análise deste recorte espacial (os resorts) e o patrimônio e processos ambientais e socioculturais locais promovidos por esses resorts. Os dados foram levantados por meio de questionários, com questões abertas sobre essas possíveis interações, aplicados aos gestores dos empreendimentos. Após essas entrevistas, de posse das informações preliminares fornecidas pelos gestores, o pesquisador teve tempo para avaliar e comprovar a veracidade dessas informações, através da utilização dos serviços, equipamentos e produtos oferecidos pelo estabelecimento e da observação direta, tanto interna como do entorno, das relações do estabelecimento com o seu entorno e com as expressões socioculturais, posteriormente descritas nos resultados da pesquisa empírica. Esse método permitiu que os resorts fossem analisados acerca da possível existência de revelação e difusão das expressões socioculturais e do ambiente local e/ou regional, que era objetivo principal da pesquisa.

Assim, investigou-se cinco resorts, em cidades pertencentes as cinco regiões do Brasil, em Manaus-AM no Norte, em Mata de São João-BA no Nordeste, em Caldas Novas-GO no Centro Oeste, em Caeté-MG no Sudeste e em Gramado-RS no Sul. Estes resorts fazem parte dos 123 considerados no universo do estudo, sendo que para a seleção dos empreendimentos para a pesquisa de campo, foi adotada a amostragem por conveniência, respeitando os critérios:

$\left.1^{\circ}\right)$ Empreendimentos cadastrados no CADASTUR que não fizessem parte do segmento de turismo cultural;

$2^{\circ}$ ) Empreendimento, resort, que estivesse sendo ofertado por uma grande agência de turismo que atua em território nacional e que na busca neste site aparecesse como opção para crianças.

Uma lista complementar de critérios para a escolha do resort foi adotada, considerando: disponibilidade de um profissional com conhecimento amplo das atividades do empreendimento, um profissional treinado ou habilitado para trabalhar com entretenimento infantil e com espaço específico para essa atividade e, ainda, não ser um parque aquático e não ser flutuante.

Turismo \& Sociedade (ISSN: 1983-5442). Curitiba, v. 12, n. 1, p. 64-81, janeiro-abril de 2019. 
A seleção da amostra envolveu os estados do Amazonas, Bahia, Goiás, Minas Gerais e Rio Grande do Sul, cada um representando, de forma aproximada, uma macrorregião brasileira. De acordo com dados extraídos do site oficial de Cadastro Turístico no Brasil, CADASTUR, a região norte possui dois resorts cadastrados, ambos no Estado do Amazonas, localizados em Manaus. A região Nordeste tem 67, com destaque para o estado da Bahia com 29 resorts, número três vezes maior do que o de Pernambuco ou do Rio Grande do Norte, cada um com 9. A região Centro-Oeste conta com 3 resorts cadastrados, enquanto a região Sudeste tem 34, sendo que o estado de São Paulo tem 21, Rio de janeiro tem 9 e no estado de Minas Gerais existem 4. A região Sul tem 16 resorts cadastrados, sendo equilibrado entre Paraná e Rio Grande do Sul com, respectivamente, 7 e 6 empreendimentos, enquanto Santa Catarina tem 3 desses empreendimentos cadastrados. No Rio Grande do Sul, os resorts cadastrados estão localizados nas cidades de Nova Petrópolis, Bento Gonçalves, Viamão e Gramado. Nesta última cidade está localizado o resort onde foi feita a pesquisa de campo na região Sul.

A partir desse universo, a amostra foi composta por um resort localizado no estado da Bahia, na cidade de Mata de São João, outro na região metropolitana de Belo Horizonte, em Minas Gerais, outro em Manaus, no Amazonas, e outro na cidade de Gramado, no Rio Grande do Sul. Também compôs a amostra um resort situado na cidade de Caldas Novas, em Goiás, que mesmo não constando no Cadastur foi selecionado por ter atingido os demais critérios definidos para a seleção da amostra.

Os resultados da pesquisa foram descritos de forma detalhada quando foram apresentados os resorts de cada uma das macrorregiões, lembrando que levaram em conta, conforme especificado na metodologia, dois pontos importantes. O primeiro ponto era composto pelos critérios culturais elencados como necessários para a sustentabilidade, como a contribuição para o reconhecimento, promoção e respeito ao patrimônio cultural das regiões e as tradições e valores culturais. Segundo, os registros nos livros do Instituto do Patrimônio Histórico e Artístico Nacional (IPHAN, 2015) como: conhecimentos e modos de fazer, enraizados no cotidiano das comunidades; rituais e festas que marcam a vivência coletiva do trabalho, da religiosidade, do entretenimento e de outras práticas da vida social; manifestações literárias, musicais, plásticas, cênicas e lúdicas; e, lugares como mercados, feiras, santuários, praças e demais espaços onde se concentram e se reproduzem práticas culturais coletivas. 


\section{A DIVERSIDADE AMBIENTAL E SOCIOCULTURAL REGIONAL NOS RESORTS BRASILEIROS}

No intuito de experimentar e revelar com mais precisão os produtos, serviços e demais características dos resorts que pudessem promover e difundir as expressões culturais locais e/ou regionais buscou-se, por meio da pesquisa de campo nos resorts que serviram de amostra para este estudo, retratar e levantar dados relacionados à influência dos aspectos culturais na percepção dos turistas. Assim, apresenta-se, nesta seção, o resultado da pesquisa realizada por meio de entrevistas, assim como as observações feitas "in loco" por um dos pesquisadores.

Os resorts, geralmente, estão localizados em zonas com potenciais atrações turísticas, em balneários, parques nacionais, serra, campos ou em regiões exóticas, que possuam praias, piscinas naturais ou quaisquer outros atrativos naturais e/ou culturais para atender a uma demanda específica de turistas em busca de descanso, lazer e praticidade sem precisar grandes deslocamentos (OMT, 2003). O próprio conceito de resort incorpora, de certa forma, uma abordagem que tende a destacar as características relacionadas ao patrimônio ambiental e sociocultural característico de cada local ou região onde ele está instalado.

Existem alguns fatores que devem ser observados pelos investidores, gestores públicos e demais atores sociais, pois algumas dessas áreas naturais, utilizadas como extensão das estruturas dos resorts, são detentoras de grande biodiversidade e rico ecossistema, passíveis de legislação própria que asseguram e exigem a sua preservação. Essa condição vem ao encontro das expectativas tanto dos turistas que optam por viajar pelo Brasil, como por interessados em investir no setor. Para tanto, os atores sociais, principalmente, os responsáveis pelo desenvolvimento e comercialização desses espaços devem garantir o progresso e o desenvolvimento turístico protegendo e promovendo o patrimônio natural e cultural brasileiro, sem prejuízo aos lugares e consequentemente, às futuras gerações (OMT, 2003).

\subsection{O PAISAGISMO DOS RESORTS E A CULTURA LOCAL}

Os resorts têm como uma de suas principais características a ambientação junto à natureza como parte integrante da experiência da hospedagem, onde suas áreas externas, geralmente, são seu ponto alto e muito comumente, confundido como áreas de propriedade do empreendimento. O paisagismo neste tipo de meio de hospedagem acompanha as propostas de atividades do mesmo, ambientando cada experiência oferecida, seja ela de entretenimento, gastronômica, de descanso ou contemplação, por exemplo. Todos os resorts que fazem partem 
da amostra do estudo integram perfeitamente a natureza local e, de acordo com seus gerentes, atingem alto grau de promoção da cultura natural local. Todos esses empreendimentos oferecem a seus hóspedes a oportunidade de provarem a culinária local e/ou regional tanto por meio das comidas típicas e bebidas servidas. Os resorts visitados integram na sua decoração o artesanato local com materiais próprios da região.

Da mesma forma que identificam a região aos quais pertencem, nota-se uma preocupação com a divulgação de expressões culturais locais diversas, principalmente por meio da música, da dança e do artesanato. Todos possuem espaço específico destinado para apresentações de danças e de músicas ou indicam um local onde são realizadas apresentações de músicos e danças típicas locais.

Também se pode observar em todos os resorts, espaços de comercialização de artesanato confeccionado pelos artistas locais e/ou regionais, sendo que $60 \%$ desses empreendimentos, objeto da pesquisa de campo, expõem estes produtos de forma mais discreta e menos intensa, enquanto $40 \%$ (quarenta por cento) oferecem um número e uma variedade bem expressiva de peças produzidas no local e/ou na região. A maioria dos resorts (60\%) indica o comércio de produtos locais e/ou regionais de forma bem intensa.

Um aspecto que pode ser considerado negativo em relação à sustentabilidade do turismo local é que, devido à intensificação do turismo no Brasil e das visitas que são oferecidas, não só pelos resorts, mas por diferentes agentes turísticos, nota-se que estas atividades alteram os costumes e tradições locais. São exemplos, as aldeias indígenas próximas de Manaus, que acabam por não comemorar na data certa seus festejos de final de ano, pois essa é a época de alta temporada e o turismo é intenso. O mesmo ocorre no caso do "Natal Luz", em Gramado, quando a cidade fica tão lotada de turistas, que a comunidade local acaba aproveitando pouco os festejos locais, principalmente pelo fluxo intenso de carros. O que acaba alterando totalmente a rotina de compras do dia-a-dia pelo congestionamento em estabelecimentos comerciais, com destaque para os restaurantes e lancherias.

\subsection{CARACTERÍSTICAS DO RESORT DA REGIÃO NORTE}

A região Norte é o berço da floresta Amazônica, onde a beleza da biodiversidade local é difícil de ser representada, porém, na tentativa de ilustrar, são demonstradas algumas expressões culturais do interior dos resorts assim como do seu entorno que retratem um pouquinho desta realidade. O objeto da pesquisa de campo representativo dessa região está 
localizado em Manaus. São ofertados pacotes com várias atrações que podem durar até um dia inteiro, como: interação com os botos; visita ao museu do Seringal Vila Paraíso; City Tour com visita ao teatro Amazonas e Palácio da Justiça; Tour Encontro das Águas, visitando a famosa planta aquática Vitória Régia, o restaurante flutuante e a feira de artesanato local. Além destes, ainda há: o passeio de Sobrevivência na Selva, com visita a uma aldeia indígena, com caminhada na selva e reconhecimento de plantas medicinais e indígenas; a Pescaria de Piranhas e Focagem de Jacaré em canoa motorizada; Visita a Anavilhanas com parada no flutuante do boto cor de rosa e visita a comunidade de São Tomé, onde se aprecia o ritual indígena da tribo.

Nos corredores a arquitetura robusta tem destaque, com madeirões escuros, com flores e folhas esculpidas, em perfeita sintonia com os lustres, bancos e quadros e acessórios. Além de lembrar muito a mata por associação a madeira inclusive trazendo, por meio da lembrança, seu cheiro que parecia impregnado no lugar. Os quadros retratam a paisagem e a cultura indígena. Percorrendo os corredores do meio de hospedagem pode-se observar a exposição de 13 cocares indígenas representando um pouco das etnias: Xavante Bobora, Akibassa, Karajás, Tikão, Kamaworas e Kaiapor da região do alto Xingú - Amazônia. Estes cocares, geralmente confeccionados com subprodutos da fauna local, estão expostos no resort porque fazem parte do Programa de Educação Ambiental do Zoológico Tropical Manaus numa parceria com o IBAMA.

Através do cardápio, pode-se perceber a presença da culinária típica da região, como é o caso do peixe Tucunaré com farinha do Uarini, pimenta de cheiro, salada Amazonas (alface, tomate, cubos de queijo coalho e croutons com molho de castanha da Amazônia), palmito de pupunha, e outros. Quanto aos doces, além do açaí, a castanha da Amazônia ou do Pará é sempre utilizada em tortas e como ornamento para outros docinhos. O café da manhã oferece uma variedade de frutas típicas, como o suco de cupuaçu, o creme de açaí, a banana com casca, tapioca feita com a massa da mandioca e recheada de tucumã e queijo coalho dentre outros recheios. São oferecidas visitas à comunidade flutuante, onde se pode observar as pessoas vivendo em casas flutuantes, um passeio até o "Encontro das Águas”, o encontro das águas escuras do Rio Negro com as águas barrentas do Rio Solimões. Além destes atrativos, os turistas podem percorrer trilhas para conhecer o ecossistema nativo, com orientações sobre ervas medicinais e formas de sobrevivência na floresta, assim como visitas para observar plantas nativas, como a vitória régia, orquídeas e a sumaumeira, que pode chegar a 60 metros de altura.

$\mathrm{Na}$ região amazônica se encontra a maioria dos povos indígenas, sendo possível conhecer, por meio de um serviço prestado pelo resort analisado, um pouco do seu modo de viver, suas tradições e crenças, além do seu rico artesanato. Os passeios são realizados com o

Turismo \& Sociedade (ISSN: 1983-5442). Curitiba, v. 12, n. 1, p. 64-81, janeiro-abril de 2019. 
acompanhamento de um experiente guia turístico que faz o reconhecimento do local para futuros trabalhos em parceria com a aldeia e o filho do Cacique, responsável pela recepção e negociação das atividades na área.

\subsection{CARACTERÍSTICAS DO RESORT DA REGIÃO NORDESTE}

O resort está situado no estado da Bahia, na região turística denominada Costa dos Coqueiros, a $75 \mathrm{~km}$ do aeroporto internacional de Salvador. A maioria da mão-de-obra empregada nesses empreendimentos é formada por habitantes da região, sendo este o maior empregador da mão-de-obra local. Nesse resort a cultura local é percebida desde a recepção através do uniforme de alguns funcionários onde a camisa os homens possuem estampas ou detalhes tropicais e o das mulheres são os vestidos de baianas, turbante na cabeça e seus muitos colares e pulseiras que tornam sua indumentária característica da região.

Dentro do empreendimento, em seus diversos espaços de lazer, foi construída uma vila, que reproduz, na sua essência, um típico vilarejo baiano, onde o espaço cenográfico reflete vários aspectos arquitetônicos da cultura baiana. Neste cenário encontra-se a igreja localizada em frente à praça, onde os cidadãos se encontram para as mais diversas conversas; o comércio do vilarejo que disponibiliza aos turistas artesanato feito pela comunidade local e regional, com madeira, sementes, fibras, casca de coco, conchas do mar além de diversas essências desenvolvidas na região. $\mathrm{O}$ vilarejo possui também um centro gastronômico com a culinária típica. Todos os dias são ofertados aos turistas programas que envolvem o folclore local, através de oficinas de arte e por meio de apresentações musicais, teatrais, contos, danças, e mostras de artistas plásticos, geralmente representados por grupos das comunidades locais.

Está sendo criado um lugar próprio para os artesãos locais, sendo que hoje eles encontram-se num pequeno espaço, na entrada da vila. As artesãs, muitas vezes premiadas, que fazem as bolsas feitas da palha de piaçava fazem parte de uma cooperativa de artesãs da região que recebem cursos e capacitações para produzir bolsas, carteiras, chapéus, tapetes, e objetos de decoração que são vendidos na Praia do Forte e em vários outros pontos turísticos, inclusive, no próprio resort. 


\subsection{CARACTERÍSTICAS DO RESORT DA REGIÃO CENTRO-OESTE}

O resort está localizado em Caldas Novas, no estado de Goiás, a 160 Km de Goiânia. A região é riquíssima em belezas naturais e fica envolta pela Serra de Caldas o que a torna rica em belezas naturais, principalmente, por suas águas termais abundantes, grande diferencial desta região. A diversidades natural e histórica no estado de Goiás se mantém em equilíbrio através da criação de destinos turísticos com o propósito de evidenciar os pontos fortes de cada localidade que os formam: Caminho do Sol; Caminho do Ouro, Caminho da Biosfera e, Caminho das Águas onde encontra-se a cidade de Caldas novas, localidade onde situa-se o resort objeto da pesquisa.

Esse empreendimento segue padrões internacionais e seu sucesso é atribuído à parceria com os mais importantes e conceituados consultores de hotelaria de luxo, gastronomia, decoração e implantação hoteleira. Foi contratado um profissional específico que está construindo cenários junto ao ambiente natural do empreendimento direcionado para as crianças, com a presença de mascotes como um índio, o tatu bola, a arara azul e outros personagens que aparecem no meio da mata. Também são realizadas atividades para assim compor um cenário.

A culinária da região Centro-Oeste oferecida no resort é bem diversificada, principalmente, pela migração das demais regiões brasileiras, inclusive de outros países. Porém, uma das maiores influências constatadas é a dos povos indígenas, onde o arroz e a galinhada com pequi assim como os peixes do Pantanal - como o pintado, pacu e dourado - formam os principais pratos. Há ainda o "boi no rolete" e o "empadão goiano", sempre mencionados quando se pergunta sobre a culinária local. O café da manhã, oferece uma variedade de frutas, inclusive as típicas, como o suco de cupuaçu, o creme de açaí, a banana com casca, tapioca feita com a massa da mandioca e recheada de tucumã e queijo coalho dentre outros recheios.

A partir das 19:00 horas está à disposição dos hóspedes um jantar (buffet) com um show de músicas e danças típicas da região. O resort conta com espaço destinado para músicos locais fazerem apresentações, onde dispõe de um piano para as apresentações pré-agendadas e divulgadas pelo meio de hospedagem. Esse empreendimento proporciona a seus hóspedes passeios pela cidade para conhecerem a arquitetura do centro histórico da cidade e as belezas naturais do Parque Estadual Serra de Caldas, com suas cachoeiras e vertentes de águas termais, que atraem visitantes todos os finais de semana. Neste lugar se localiza a primeira fonte de águas termais, onde a água chega a $70^{\circ} \mathrm{C}$.

No Parque Estadual Serra de Caldas encontra-se um museu que desvenda a flora e fauna

Turismo \& Sociedade (ISSN: 1983-5442). Curitiba, v. 12, n. 1, p. 64-81, janeiro-abril de 2019. 
local por meio de aves e animais empalhados assim como peixes variados mantidos em vidros e conservados com produtos apropriados para tal fim. Destacam-se as seguintes espécies: jacarés, capivaras, peixes (dourado, pintado, curimbatá, pacu), ariranhas, onça-pintada, macaco-prego,veado-campeiro, lobo-guará, cervo do pantanal, tatu, bicho preguiça, tamanduá, lagartos, cágados, jabutis, cobras (jiboia e sucuri) e pássaros (tucanos, jaburus, garças, papagaios, araras, emas, gaviões).

Quanto às festividades, as festas julinas, como são comumente chamadas pela população local, justamente por ocorrerem no mês de julho, têm programação durante todo o mês no Estado. No resort existe uma programação específica para esta festividade, a respeito da qual foi relatado um planejamento para ampliar as parcerias locais e o fornecimento de comidas e bebidas típicas da região. Durante todo o ano o empreendimento dispõe de espaços específicos para artistas locais e músicos que apresentam seus trabalhos aos turistas hospedados, utilizando estes espaços para a comercialização de seus produtos.

\subsection{CARACTERÍSTICAS DO RESORT DA REGIÃO SUDESTE}

O resort está localizado no estado de Minas Gerais, aproximadamente $70 \mathrm{~km}$ do centro de Belo Horizonte. Ao chegar no meio de hospedagem já se percebe o ar de fazenda, mas em conjunto com um ambiente bem planejado e munido de alta tecnologia e sofisticação e uma exuberante flora local. Os amplos corredores do estabelecimento trazem em suas paredes o destaque da flora e de lugares turísticos através de pinturas feitas por artistas locais.

Após o check-in o recepcionista já informa acerca da agência de viagens que disponibiliza diversos passeios pelos pontos turísticos da cidade e, também, que há atividades para adultos e crianças que podem ser feitas diariamente. A agência dispõe de programação de passeios ao seu entorno, inclusive para a Serra da Piedade, local em que se localiza a igreja da Nossa Senhora da Piedade que é a padroeira de Minas Gerais e que faz parte do Caminho Religioso da Estrada Real (C.R.E.R.). A Igreja da Nossa Senhora da Piedade fica na Serra da Piedade, no alto da montanha, a 1.746 metros de altitude, a $48 \mathrm{~km}$ da capital mineira. No interior do meio de hospedagem são comercializados diversos produtos locais, onde se destaca o queijo, o vinho e artesanatos em pedras semipreciosas.

O resort dispõe de pistas de boliche, sala de cinema, complexo de piscinas, inclusive térmicas, spa com hidromassagem, boate, um mini shopping, vários restaurantes e bares além de espaços planejados para crianças de todas as idades que contam com especialistas em diversão. $\mathrm{O}$ empreendimento possui ainda a casa da árvore, casinha para as crianças e a 
Fazendinha, que conta com vários animais. Há passeios a cavalo e de pônei e, também, uma mini vaca da qual é possível tirar leite pela manhã, uma das atividades oferecidas para as crianças denominada "um dia na roça".

Nos restaurantes há pratos típicos locais ou mineiros, descrito no cardápio. Alguns pratos como: o surubim, jiló, angu, tropeiro, rabada com agrião, alcatra ao molho de cerveja preta, couve com torresmo, feijão preto com defumados, eisbein (joelho defumado), repolho refogado, frango a mineira, quiabo, tutu à mineira, caldo mineiro, canjiquinha com costelinha, carne de sol, frango ensopado com quiabo, polenta com moelinha ensopada, torresmo com mandioca e várias receitas com diferentes tipos de queijos.

\subsection{CARACTERÍSTICAS DO RESORT DA REGIÃO SUL}

O resort está situado na cidade de Gramado, no Rio Grande do Sul, a $110 \mathrm{Km}$ do aeroporto internacional Salgado Filho. O empreendimento na serra gaúcha está a uma quadra de uma das principais ruas da cidade e cercado por um bosque de araucárias, onde os turistas podem usufruir não só do conforto, como, também, das diversas atividades oferecidas internamente no meio de hospedagem como também terão acesso aos principais eventos da cidade, que ficam a próximos do mesmo.

No resort são comercializados diversos produtos locais, onde destaca-se o chocolate de gramado, a erva mate, cuias, bombas, artigos em couro como sapatos, bolsas e acessórios. Nos corredores do estabelecimento há galerias em vidro indicando locais de compra, e na parte externa são disponibilizados produtos típicos regionais. Ainda nas paredes dos corredores, todos os quadros são de um artista gaúcho, que logo de chegada, segundo a gerente do meio de hospedagem, já são reconhecidos. O estabelecimento oferece diversas atividades para adultos e crianças com espaço específico com monitores que os acompanham em atividades de manhã à noite sendo que estas variam de passeios pelo bosque até o aprendizado de como fazer "comidinhas" para as crianças junto ao chef do resort.

Dentro do escopo desta pesquisa, um espaço importante é o restaurante especializado em carnes nobres assadas, que referenda a decoração e a culinária dos pampas, um espaço decorado com imagens que lembram fazendas, uma vista que pode ser apreciada durante as refeições. Os trajes dos seus funcionários são típicos: homens com bombachas, camisas com mangas largas, lenço vermelho, chapéu e uma faca atravessada na cintura. E, as mulheres com vestido de prenda e o cabelo preso com uma linda flor. 


\section{CONSIDERAÇÕES FINAIS}

A diversidade cultural de cada região foi verificada internamente nos resorts, por meio de espaços concedidos para a arte de artistas locais e/ou regionais, pela vestimenta dos funcionários, pela decoração do ambiente interno, através de móveis e utensílios utilizados. Também externamente se verifica a presença da cultura regional, entre outras, por meio da adaptação da flora regional nos jardins e dos espaços concedidos para o comércio de produtos regionais.

A culinária foi a melhor forma de expressão da cultura local e regional transmitida aos turistas. Porém, o que chama a atenção também é a forma intensa como os resorts analisados promovem o seu entorno, tanto internamente por meio da venda de produtos da região, como externamente através da indicação de lugares para visitação pelos turistas, contribuindo, assim, para a promoção e difusão da diversidade de expressões culturais locais.

Esse meio de hospedagem tem como uma de suas principais características a ambientação junto à natureza como parte integrante da experiência da hospedagem, onde suas áreas externas, geralmente, são seu ponto alto, que muitas vezes são confundidas com áreas de propriedade do resort. O paisagismo neste tipo de meio de hospedagem acompanha as propostas de atividades do mesmo, ambientando cada experiência oferecida, seja ela de entretenimento, gastronômica, de descanso ou contemplação, por exemplo. Todos os empreendimentos que serviram de amostra para este estudo integram perfeitamente a natureza local e, de acordo com seus gerentes, atingem alto grau de promoção da cultura natural local.

Cada um dentro do seu estilo, os resorts integram na sua decoração o artesanato local, por meio de quadros, esculturas e outros objetos compostos de diversos materiais próprios da região como pedras, madeiras, sementes e fibras. O importante é que se percebe que todos valorizam e procuram identificar a região a que pertencem por meio do artesanato e por meio da música, da dança e do artesanato. Um aspecto relevante a ser observado a partir dos resultados deste estudo é a possibilidade de um aprofundamento da relação positiva das características dos resorts brasileiros com a preservação e conservação do patrimônio ambiental e sociocultural brasileiro, crescentemente procurada por turistas estrangeiros, que vêm ao país em busca dessas diversidades. No entanto, esta relação deveria ter maior importância, principalmente, para as populações locais e para os turistas brasileiros, que nem sempre têm a correta noção do valor dessa diversidade e do sentimento de pertencimento. 
Torna-se evidente que não só existe impacto das ações dos resorts nas expressões culturais locais como este se dá de forma positiva por meio da promoção, divulgação e atividades oferecidas. Assim propiciam a seus hóspedes o conhecimento do seu entorno e dos produtos e serviços que são oferecidos por agentes turísticos nos lugares visitados, ajudando o desenvolvimento da região por meio da geração de emprego e renda para aqueles que dependem da demanda turística. Verificou-se, também, que os resorts são grandes difusores das expressões culturais devendo, por conclusão da pesquisa, serem mais aproveitados como canal de promoção por meio de ações obrigatórias elencadas nas políticas públicas, leis e normativas, definidas para este meio de hospedagem.

E, por fim, percebe-se o esforço do setor público, em alguns locais, para normatizar a forma como se pode experimentar a cultura local sem prejudicar o meio ambiente ou a infraestrutura local. No caso de Manaus, notou-se que existe uma tentativa de evitar eventuais prejuízos às populações de animais, como é o caso da experimentação do contato com os botos cor de rosa. Para que os turistas possam tocá-los há a necessidade de alimentá-los, o que acaba por prejudicar muitas vezes a espécie pelo excesso de alimentos e o stress causado pela quantidade de turistas que querem usufruir dessa mesma experiência. Por isso, foi estipulado pelo poder público local que a segunda-feira é o dia de descanso para esses animais, não podendo receber visitas e, segundo alguns, tendo inclusive a alimentação suspensa.

\section{REFERÊNCIAS}

AMAZONAS (Estado). Cultura. Disponível em: <http://www.amazonas.am.gov.br/oamazonas/cultura/>. Acesso em: 20/05/2015.

ASSOCIAÇÃO BRASILEIRA DE NORMAS TÉCNICAS (ABNT). Meios de Hospedagem: Sistema de gestão da sustentabilidade. Rio de Janeiro: ABNT; SEBRAE, 2012.

BARBOSA, G. S. O Desafio do Desenvolvimento Sustentável. Revista Visões. 4. ed., n. 4, v. 1, p.1-11, 2008.

BARBOSA, M. A. Resort: o lazer no contexto de negócio. Licere, Belo Horizonte, v. 8, n. 2, p.99-113, 2005.

BRASIL. Ministério do Turismo. Plano Nacional de Turismo 2013-2016. Brasília, DF, 2013.

CARLOS, A. F. O mundo no lugar e o lugar no mundo. São Paulo: LABU, 2007.

GUIA DE HOTÉIS BRASIL. Guia Hotel in Site. Disponível em:

$<$ http://www.hotelinsite.com.br/>. Acesso em: 22/08/2015. 
INSTITUTO BRASILEIRO DE GEOGRAFIA E ESTATÍSTICA - IBGE. Sistema de Informações e Indicadores Culturais 2007-2010. Rio de Janeiro 2013.

INSTITUTO DE PATRIMÔNIO HISTÓRICO E ARTÍSTICO NACIONAL - IPHAN. 2015. Disponível em: $<$ http://portal.iphan.gov.br/pagina/detalhes/314 $\geq$. Acesso em: 15/05/2015.

MILL, R. C. Resorts: administração e operação. Porto Alegre: Bookman, 2003.

ORGANIZAÇÃO MUNDIAL DO TURISMO - OMT. Introdução ao turismo. São Paulo: Roca. 2001.

PEREIRA, N. S. S. Patrimônio cultural, turismo e ordenamento territorial. Turismo e Sociedade. Curitiba, v. 10, n. 3. p. 1-14, 2017.

YÚDICE, G. A conveniência da cultura: usos da cultura na era global. Belo Horizonte: UFMG, 2006.

Recebido em: 05-04-2019.

Aprovado em: 11-07-2019.

Versão aprovada para publicação em: 23-08-2019. 